\title{
Reperfusion Treatment for Acute Pulmonary Embolism
}

\author{
Rolf P. Engelberger ${ }^{1}$ Nils Kucher ${ }^{2}$ \\ ${ }^{1}$ Division of Angiology, Cantonal Hospital Fribourg, Fribourg, \\ Switzerland \\ ${ }^{2}$ Clinic of Angiology, University Hospital Zurich, Zurich, Switzerland \\ Address for correspondence Nils Kucher, MD, Clinic of Angiology, \\ University Hospital Zurich, Raemistrasse 100, 8091 Zurich, \\ Switzerland (e-mail: nils.kucher@usz.ch). \\ Hämostaseologie 2018;38:98-105.
}

\begin{abstract}
Keywords

- pulmonary embolism

- catheter-based therapy

- reperfusion therapy

- thrombolysis

Zusammenfassung

Schlüsselwörter

- Lungenembolie

- Katheter-basierte Therapie

- Reperfusionstherapie

- Thrombolyse

Due to the manifold treatment options for the management of acute pulmonary embolism, state-of-the-art management requires risk stratification for choosing the adapted treatment for each patient. Reperfusion therapy is an integral part of therapy for patients with pulmonary embolism at high risk for mortality, but its role in patients with intermediate risk pulmonary embolism is more debated. The largest amount of evidence exists for systemic thrombolysis, which is an efficient therapy, but at the prize of an increased bleeding risk. In recent years, various types of catheter-based reperfusion therapies have been introduced, and evidence is growing that this therapy is as efficient as systemic thrombolysis, but with a more favourable safety profile. Surgical embolectomy remains a good alternative for unstable patients, especially for those with absolute contraindications for thrombolysis or after failed systemic thrombolysis. While the early benefits of reperfusion therapy are well documented, evidence for long-term benefit is still scarce. The scope of this review is to summarize the evidence for the currently available reperfusion therapies in the management of acute pulmonary embolism.

Aufgrund der vielfältigen Behandlungsmöglichkeiten für die akute Lungenembolie erfordert das Management nach dem neuesten Stand eine Risikostratifizierung, um die angepasste Behandlung für jeden Patienten auszuwählen. Die Reperfusionstherapie ist ein wesentlicher Therapiebestandteil bei Patienten mit Lungenembolie mit hohem Mortalitätsrisiko, aber ihre Rolle bei Patienten mit Intermediärrisiko-Lungenembolie ist umstritten. Die größte Evidenz gibt es für die systemische Thrombolyse, die eine effiziente Therapie darstellt, jedoch zum Preis eines erhöhten Blutungsrisikos. In den letzten Jahren wurden verschiedene Arten von katheter-basierten Reperfusionstherapien eingeführt, und es gibt Hinweise dafür, dass diese Therapie genauso effizient ist wie die systemische Thrombolyse, aber mit einem vorteilhafteren Sicherheitsprofil. Die chirurgische Embolektomie bleibt eine gute Alternative für instabile Patienten, insbesondere für Patienten mit absoluten Kontraindikationen für Thrombolyse oder nach erfolgloser systemischer Thrombolyse. Während die frühen Vorteile der Reperfusionstherapie gut dokumentiert sind, ist der Nachweis für einen langfristigen Nutzen immer noch gering. Ziel dieser Übersichtsarbeit ist es, die Evidenz für die derzeit verfügbaren Reperfusionstherapien bei der Behandlung der akuten Lungenembolie zusammenzufassen.
\end{abstract}

received

July 31,2017

accepted after revision

January 17, 2018
Copyright @ 2018 Schattauer 


\section{Risk Stratification}

Venous thromboembolism (VTE) encompassing deep vein thrombosis (DVT) and pulmonary embolism (PE) is the third most frequent cardiovascular disease worldwide with an annual incidence of 100 to 200 per 100,000 inhabitants. ${ }^{1}$ PE spans a broad spectrum of clinical outcomes but remains a potentially life-threatening disease. ${ }^{2,3}$ PE-related mortality is mainly due to right ventricular (RV) failure as a consequence of pressure overload. ${ }^{4}$ Early clinical outcomes therefore mainly depend on initial hemodynamic status and the extent of RV dysfunction.

To improve prognosis and avoid potentially dangerous overtreatment, therapeutic interventions for PE patients should be tailored to the patient's individual risk for adverse early and ideally late outcomes, and range from ambulatory treatment or clinical surveillance without anticoagulation to extracorporeal membrane oxygenation and surgical embolectomy. ${ }^{5,6}$ Various prognostic models have been developed to classify patients into risk groups. The most widely applied are the (simplified) Pulmonary Embolism Severity Index (sPESI and PESI) which stratifies patients by clinical parameters only, ${ }^{7}$ and the European Society of Cardiology (ESC) model which further includes imaging and biomarker test results of RV dysfunction and myocardial injury. ${ }^{4}$ According to the ESC risk classification, high-risk PE patients are defined as haemodynamically unstable patients with cardiogenic shock, sustained systemic arterial hypotension or the need for cardiopulmonary resuscitation. ${ }^{4}$ High-risk PE is associated with a 90 -day mortality rate of $>50 \%{ }^{8}$ Haemodynamically stable patients are assessed by a validated clinical prognostic score, preferably the sPESI or PESI. A 30-day mortality rate of 5 to $25 \%$ was reported for PE patients with a SPESI $\geq 1$ point or a PESI class $\geq 3$, and they are classified as intermediate-risk PE. Following the recent publication of the Pulmonary Embolism International Thrombolysis (PEITHO) trial, ${ }^{9}$ the ESC guideline further stratifies intermediate-risk patients into intermediatehigh and intermediate-low risk patients ( - Fig. 1). Patients with low-risk PE are haemodynamically stable with a low (s)PESI score, and if assessed neither have RV dysfunction nor elevated cardiac biomarkers; these patients usually have excellent short-term prognosis once therapeutic levels of anticoagulation are established. ${ }^{10}$ The initial stratification of PE patients into different risk groups has an important impact on the various treatment options, in particular for the use of reperfusion therapy. ${ }^{3,11,12}$

\section{Reperfusion Treatment}

\section{Short-Term Benefit}

Early reperfusion therapy for acute PE improves the right-heart haemodynamics and facilitates the right ventricle recovery by removing obstructing thrombi from the large pulmonary arteries, improves oxygenation by correcting ventilation/perfusion mismatch and, finally, improves symptoms and survival. $6,11,13,14$ The largest amount of evidence for the shortterm outcomes currently exists for systemic thrombolysis. A recent meta-analysis including 15 randomized controlled trials (involving 2,057 patients) showed that systemic thrombolysis in addition to standard therapy of anticoagulation alone reduced overall (odds ratio [OR], 0.59, 95\% confidence interval [CI]: 0.360.96) and PE-related mortality (OR, 0.29; 95\% CI: 0.14-0.60), death or treatment escalation (OR, $0.34 ; 95 \% \mathrm{CI}: 0.22-0.52)$ and PE recurrence (OR, 0.50; 95\% CI: 0.27-0.94). ${ }^{15}$ However, no significant reduction in overall mortality was observed after exclusion of studies which enrolled high-risk PE patients. ${ }^{15}$ The results of this meta-analysis for patients with intermediate-risk PE were largely driven by the PEITHO trial, comparing a single, weight-adapted intravenous bolus of tenecteplase with standard anticoagulation alone in 1.005 patients with intermediatehigh risk $\mathrm{PE} .{ }^{9}$ In the tenecteplase group, the primary outcome (all-cause death or haemodynamic decompensation within 7 days) was significantly reduced from 5.6 to $2.6 \%$ (OR, 0.44 ; $95 \%$ CI: $0.23-0.88)$, without reduction in overall mortality (1.2\% vs. $1.8 \%, p=0.42$ ). Another recently published small randomized trial with 83 intermediate-risk PE patients including patientoriented outcomes at 3 months' follow-up showed that a single weight-adapted bolus of tenecteplase in addition to anticoagulation with low-molecular weight heparin significantly reduced the composite primary outcome including death, circulatory shock, intubation or major bleeding within 5 days or recurrent PE, poor functional capacity (RV dysfunction with either dyspnoea at rest or exercise intolerance) or a low health-related quality of life score at 3 months' follow-up (15\% vs. $37 \%$; $p=0.027$ ). The main drivers of this effect were the composite endpoint of impaired functional capacity and a low self-assessment of physical wellness. ${ }^{16}$

\section{Long-Term Benefit}

While short-term benefits are well documented, at least for high-risk patients, long-term benefits remain controversial. The recently published long-term data (mean follow-up of 37.8 months) of 709 patients from the PEITHO trial revealed that there appears to be no reduction in overall mortality (20.3\% for the tenecteplase group vs. $18.0 \%, p=0.43$ ), with the majority of deaths due to comorbidities and underlying diseases, no reduction in functional limitation or persistent shortness of breath ( $36.0 \%$ vs. $30.1 \% ; p=0.23$ ), with most patients reporting mild exertional dyspnoea, and no reduction in chronic thromboembolic pulmonary hypertension (CTEPH; $2.2 \%$ vs. $3.2 \%, p=0.79$ ). ${ }^{17}$ The high incidence of persistent dyspnoea and decreased exercise capacity after acute PE has recently lead to the introduction of the concept of the post-PE syndrome, with CTEPH as its most severe presentation. ${ }^{14,18}$ The Evaluation of Long-term Outcome after Pulmonary Embolism (ELOPE) study confirmed this concept, with almost half of patients presenting with exercise limitation and dyspnoea, that adversely influenced health-related quality of life and walking distance at 1 year after a first episode of acute symptomatic PE. ${ }^{19}$

\section{Which Are the Reperfusion Options in 2017?}

Systemic thrombolysis and surgical pulmonary embolectomy have been the only reperfusion therapy options for many decades. Since the first description of the Greenfield 


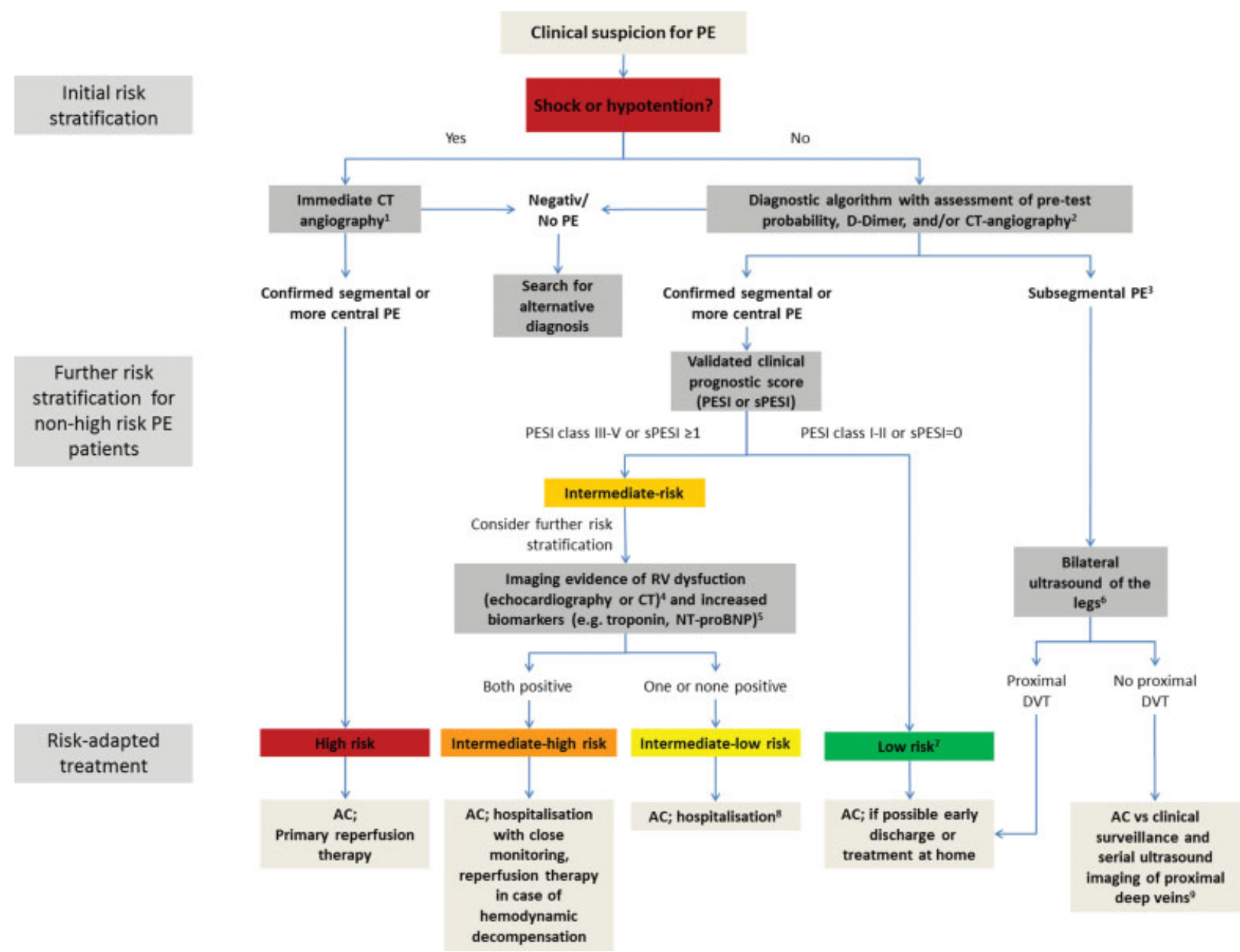

Fig. 1 Diagnostic and therapeutic algorithm for the management of acute pulmonary embolism according to the European Cardiology Society ${ }^{4}$ and the American College of Chest Physician ${ }^{5}$ consensus guidelines (adapted from Engelberger et al ${ }^{44}$ ). Note: ${ }^{1}$ If $\mathrm{CT}$ angiography not immediately available, perform echocardiography looking for signs of RV overload. In case of positive echocardiography or direct visualization of mobile thrombus in the RV, a reperfusion therapy can be performed, or the finding is confirmed by CT angiography if the patient is stabilized. ${ }^{2}$ In case of low/intermediate (or 'unlikely' when a binary score is used) pre-test probability, D-dimers are measured; in case of high (or 'likely') pretest probability or positive D-dimers, perform a CT angiography. ${ }^{3}$ Diagnostic criteria for sub-segmental PE are summarized in Kearon et al. ${ }^{5}{ }^{4}$ If a echocardiography has already been performed during diagnostic workup and detected RV dysfunction, or if the CT angiography has shown RV enlargement (RV/LV ratio $\geq 0.9$ ), blood biomarkers should be determined (except for in cases in which primary reperfusion therapy is not a therapeutic option due to severe comorbidity or limited life expectancy). ${ }^{5}$ If positive biomarkers were found during diagnostic workup (e.g. positive troponin for chest pain), an echocardiography should be considered to assess RV function, or RV size should be (re)assessed on CT angiography. ${ }^{6}$ If no anticoagulation therapy is an option for patients with a sub-segmental PE, a proximal DVT of the legs or a DVT at other highrisk locations (e.g. upper extremities with central venous catheters) should be excluded by ultrasonography. ${ }^{7}$ Patients with a PESI Class I-II, or with SPESI of 0 points, but with positive biomarkers or signs of RV dysfunction on imaging tests, are also to be classified into the intermediate-low risk category. These patients are probably not candidates for home treatment. ${ }^{8}$ Monitoring should be considered for patients with confirmed PE and positive biomarkers, even if there is no evidence of RV dysfunction on imaging tests. ${ }^{9}$ Individual decision depending on patient's risk for recurrent or progressive VTE and for bleeding complications. In patients with risk factors for recurrent or progressive VTE (e.g. hospitalization, reduced mobility, active cancer-particularly if metastatic or being treated with chemotherapy, or absence of reversible risk factor for VTE such as recent surgery), or with low cardiopulmonary reserve or marked symptoms that cannot be attributed to another conduction, anticoagulation is suggested; otherwise, clinical surveillance supplemented by serial ultrasonography of the proximal deep veins of both legs is suggested. Abbreviations: AC, anticoagulation; CT, computed tomography; DVT, deep vein thrombosis; LV, left ventricle; PE, pulmonary embolism; PESI, pulmonary embolism severity index; RV, right ventricle; sPESI, simplified PESI; VTE, venous thromboembolism.

embolectomy device in $1971,{ }^{20}$ several catheter-based techniques have been developed and are nowadays a valuable alternative to the aforementioned therapies. ${ }^{13}$

\section{Systemic Thrombolysis}

Current consensus guidelines unanimously recommend primary systemic thrombolysis as first-line treatment in acute high-risk PE. ${ }^{4,5,11}$ Different treatment regimens with recombinant tissue plasminogen activator (rtPA), urokinase and streptokinase have been approved by the Food and Drug Administration. ${ }^{11}$ A typically used regimen is a 2-hour continuous intravenous infusion of $100 \mathrm{mg}$ rtPA, but in case of cardiac arrest due to acute PE, accelerated regiments (e.g. $50 \mathrm{mg}$ over 15 minutes) can be administered. ${ }^{4,6}$ The main drawback of systemic thrombolysis is the high risk for 
bleeding complications, which has been confirmed by the large-scale PEITHO trial. Major bleeding complications according to the International Society on Thrombosis and Haemostasis (ISTH) definition ${ }^{21}$ occurred in $11.5 \%$ in the tenecteplase group and $2.4 \%$ in the control group, and haemorrhagic stroke was observed in 2 and $0.2 \%$, respectively $(p<0.01){ }^{9}$ In the meta-analysis by Marti et al, the reported rate of fatal or intracranial haemorrhage was $1.7 \%$ in the systemic thrombolysis group and $0.3 \%$ in the control group (OR, 3.18; 95\% CI: $1.25-8.11 ; p=0.008) .{ }^{15}$ Physician's fear from bleeding complications and the contraindications ( - Table 1) are among the main reasons that systemic thrombolysis is nowadays withheld in more than two-thirds of patients with high-risk PE. ${ }^{22,23}$ One of the strategies to reduce bleeding complications is to administer reduced-dose thrombolytic regimens. According to a meta-analysis including three studies with a direct comparison between low-dose (up to $50 \mathrm{mg}$ rtPA) and standard-dose rtPA, there was no significant difference in overall mortality or major bleeding complications, although there was a trend towards fewer major bleeding complications with low-dose (OR, 0.5; 95\% CI: $0.17-1.45){ }^{24}$ In the absence of convincing evidence, authors therefore recommend using standard-dose over low-dose when rtPA is used. ${ }^{24}$

Another strategy to reduce bleeding complications is to develop prediction tools for better patient selection. By analysing a large nationwide inpatient database of 9,703

Table 1 Absolute and relative contraindications for systemic thrombolysis according to the European Society of Cardiology 4

\begin{tabular}{|l|}
\hline Absolute contraindications ${ }^{\text {a }}$ \\
\hline $\begin{array}{l}\text { - Haemorrhagic stroke or stroke of unknown origin at any } \\
\text { time }\end{array}$ \\
\hline - Ischemic stroke in the preceding 6 mo \\
\hline - Central nervous system damage or neoplasms \\
\hline $\begin{array}{l}\text { - Recent major trauma/surgery/head injury in the preceding } \\
3 \text { wk }\end{array}$ \\
\hline - Gastrointestinal bleeding within the last month \\
\hline - Known bleeding risk \\
\hline Relative contraindications \\
\hline - Transient ischemic attack in the preceding 6 mo \\
\hline - Oral anticoagulant therapy \\
\hline - Pregnancy, or within 1 wk postpartum \\
\hline - Non-compressible puncture site \\
\hline - Traumatic resuscitation \\
\hline - Refractory hypertension (systolic blood pressure \\
\hline$>180$ mm Hg) \\
\hline - Advanced liver disease \\
\hline - Infective endocarditis \\
\hline - Active peptic ulcer \\
\hline
\end{tabular}

${ }^{a}$ Absolute contraindications to thrombolysis might become relative in a patient with immediately life-threatening high-risk pulmonary embolism (PE).
PE patients which were treated with thrombolytic drugs, 4 independent prognostic factors for intracranial haemorrhage were identified and summarized in the PE-CH score: pre-existing Peripheral vascular disease (1 point), age greater than 65 years (Elderly) (1 point), prior Cerebrovascular accident with residual deficit (5 points) and prior myocardial infarction (Heart attack) (1 point). Scores of 0, 1, 2 and $\geq 5$ points were associated with intracerebral haemorrhage $(\mathrm{ICH})$ risks of $1.2,1.9,2.4$ and $17.8 \%$, respectively. ${ }^{25} \mathrm{~A}$ prospective validation of this score is not yet available.

\section{Catheter-Based Reperfusion Therapy}

Many different types of percutaneous catheter-based techniques have been used to remove obstructing thrombi from the main or lobar pulmonary arteries. ${ }^{13}$ Contemporary catheter-based reperfusion techniques for PE can broadly be classified as interventions with local administration of thrombolytic drugs and those without thrombolytic drugs (-Table 2). The latter techniques can be used for patients with absolute contraindications to thrombolysis. The former have the advantage of administering the thrombolytic drug directly into the obstructing thrombus. This is likely to increase both efficiency and safety by increasing the thrombolytic drug concentration within the thrombus, and decreasing the concentration in the systemic circulation compared with peripherally administered systemic thrombolysis, where the drug is likely to be shunted into nonoccluded arteries and not to reach obstructive thrombus as shown in an animal flow dynamics model by Schmitz-Rode et al. 26

Unfortunately, there is no study with a direct comparison between catheter-based reperfusion therapy and systemic thrombolysis, and only one randomized controlled trial comparing catheter treatment with anticoagulation alone-the ULTrasound accelerated thrombolysIs of pulMonAry embolism (ULTIMA) trial $^{27}$-has been published so far. The ULTIMA trial was performed with the EkoSonic Endovascular System (EKOS Corporation; Bothell, Washington, United States), the only available catheter system for ultrasound-assisted catheter-directed thrombolysis (USAT; - Fig. 2). The emitted lowenergy, high-frequency intravascular ultrasound is thought to facilitate the delivery of thrombolytic drug into the thrombus by causing reversible loosening of the clot ultrastructure, an effect that may create additional binding sites, and by pushing the thrombolytic drug into the thrombus by acoustic streaming. ${ }^{28,29}$ In ULTIMA, a standardized USAT treatment protocol (20 mg of rtPA for patients with bilateral and $10 \mathrm{mg}$ for patients with unilateral device placement during 15 hours) was compared with usual care of unfractionated heparin in a total of 59 intermediate-risk PE patients, with the reduction of echocardiographic right-to-left ventricular ratio (RV/LV) at 24 hours as primary endpoint. In the USAT group, the RV/LV ratio was reduced from $1.28 \pm 0.19$ at baseline to $0.99 \pm 0.17$ at 24 hours ( $p<0.001$ ), with no significant decrease in the control group $(1.20 \pm 0.14$ vs. $1.17 \pm 0.20 ; p=0.31)$. Although there was a late 'catch-up' of RV enlargement in patients with heparin alone, there was a trend for greater 
Table 2 Catheter-based interventional techniques and devices for pulmonary embolism

\begin{tabular}{|c|c|c|c|}
\hline \multicolumn{2}{|c|}{ Catheter interventions with thrombolysis } & \multicolumn{2}{|c|}{ Catheter interventions without thrombolysis } \\
\hline Technique & Device examples & Technique & Device examples \\
\hline \multirow[t]{4}{*}{$\begin{array}{l}\text { Catheter-directed } \\
\text { thrombolysis }\end{array}$} & \multirow{4}{*}{$\begin{array}{l}\text { UniFuse (AngioDynamics, } \\
\text { Latham, New York, United } \\
\text { States) or Cragg-McNamara } \\
\text { (ev3 Endovascular, } \\
\text { Plymouth, Minnesota, } \\
\text { United States) 4-5F infusion } \\
\text { catheters, with 10-20 cm } \\
\text { infusion length }\end{array}$} & \multirow[t]{4}{*}{ Aspiration thrombectomy } & $\begin{array}{l}\text { Aspirex } 8 \mathrm{~F}, 10 \mathrm{~F} \text { catheter } \\
\text { (Straub Medical, } \\
\text { Switzerland): rotational } \\
\text { thrombectomy }\end{array}$ \\
\hline & & & $\begin{array}{l}\text { Angiovac suction cannula } \\
\text { (AngioDynamics, Latham): } \\
\text { veno-venous bypass system } \\
\text { with } 26 \mathrm{~F} \text { access for inflow and } \\
16-20 \mathrm{~F} \text { access for outflow }\end{array}$ \\
\hline & & & $\begin{array}{l}\text { Indigo Mechanical Throm- } \\
\text { bectomy System (Penumbra, } \\
\text { Alameda, California, United } \\
\text { States): 8F vacuum assisted } \\
\text { aspiration with mechanical } \\
\text { clot engagement }\end{array}$ \\
\hline & & & $\begin{array}{l}\text { Sheath with detachable hae- } \\
\text { mostatic valve } 8-9 F \text { (Argon } \\
\text { Medical Devices, Athens, } \\
\text { Texas, United States) plus } \\
\text { multi-purpose guide catheter } \\
\text { (8-9F) plus aspiration syringe } \\
(60 \mathrm{~mL})\end{array}$ \\
\hline $\begin{array}{l}\text { Ultrasound-assisted catheter- } \\
\text { directed thrombolysis }\end{array}$ & $\begin{array}{l}\text { EkoSonic } 5.2 \mathrm{~F} 12-\mathrm{cm} \\
\text { treatment zone device } \\
\text { (EKOS, Bothell, Washington, } \\
\text { United States) }\end{array}$ & Mechanical thrombectomy & $\begin{array}{l}\text { Flowtriever (Inari Medical, } \\
\text { Irvine, California, United } \\
\text { States): } 20 \text { F device with three } \\
\text { self-expanding nitinol discs } \\
\text { entrapping the thrombus } \\
\text { with simultaneous aspiration }\end{array}$ \\
\hline \multirow{2}{*}{$\begin{array}{l}\text { Rheolytic thrombectomy } \\
\text { plus catheter-directed } \\
\text { thrombolysis }\end{array}$} & \multirow{2}{*}{$\begin{array}{l}\text { Angiojet 6F PE thrombect- } \\
\text { omy with Power Pulse } \\
\text { thrombolysis (Boston } \\
\text { Scientific, Minneapolis, } \\
\text { Minnesota, United States) }\end{array}$} & \multirow[t]{2}{*}{ Rheolytic thrombectomy } & $\begin{array}{l}\text { Angiojet 6F PE catheter } \\
\text { (Boston Scientific) }^{\mathrm{a}}\end{array}$ \\
\hline & & & $\begin{array}{l}\text { Hydrolyzer (6-7F, Cordis, } \\
\text { Miami, Florida, United } \\
\text { States) }\end{array}$ \\
\hline \multirow[t]{2}{*}{ Combined techniques } & \multirow[t]{2}{*}{$\begin{array}{l}\text { For example, pigtail frag- } \\
\text { mentation (5F) plus Angiojet } \\
6 \text { F PE thrombectomy with } \\
\text { Power Pulse thrombolysis }\end{array}$} & Thrombus fragmentation & $\begin{array}{l}\text { Pigtail catheter ( } 5-6 \mathrm{~F}) \text { or } \\
\text { peripheral balloon catheters } \\
\text { (6-7F, balloon diameter } 5-10 \\
\text { mm) }\end{array}$ \\
\hline & & Combined techniques & $\begin{array}{l}\text { For example, pigtail frag- } \\
\text { mentation (5F) plus Aspirex } \\
8 \mathrm{~F}, 10 \mathrm{~F} \text { thrombectomy }\end{array}$ \\
\hline
\end{tabular}

${ }^{a}$ Black box warning for use in pulmonary arteries by the Food and Drug Administration because of reports of asystole and haemodynamic collapse.

improvement in $\mathrm{RV} / \mathrm{LV}$ ratio from baseline to 90 days in favour of USAT $(0.35 \pm 0.22$ for the USAT vs. $0.24 \pm 0.19$ for the heparin alone group; $p=0.07$ ). In both the study groups, no major bleeding complications occurred. ${ }^{27}$

The favourable results with USAT were recently confirmed in the SEATTLE-II study, a prospective single-arm, multicentre trial including 150 patients with acute PE (31 highrisk and 119 intermediate-risk PE) showing a significant reduction in $\mathrm{RV} / \mathrm{LV}$ ratio (1.55 vs. $1.13 ; p<0.001)$ and anatomic thrombus burden at 48 hours, a major bleeding rate-defined as moderate or severe bleeding according to the GUSTO criteria ${ }^{30}$-at 30 -day of $10 \%$, without any intracranial haemorrhage, and a 30-day mortality rate of $2.7 \% .{ }^{31} \mathrm{~A}$ meta-analysis on USAT for the treatment of intermediate- and high-risk PE published in 2018 including 15 studies with a total of 655 patients found a pooled incidence of all-cause mortality of $3.2 \%$ and a major bleeding rate of $5.5 \% .^{32}$ In summary, USAT seems to have a similar positive effect on RV haemodynamics, with similar death rates but lower major bleeding rates, even in patients at increased bleeding risk, ${ }^{33}$ and most importantly, a clear advantage regarding fatal and intracranial bleeding compared with systemic thrombolysis, ${ }^{32,34}$ although a case report on intracranial haemorrhage has recently been published. ${ }^{35}$

It remains unclear if the use of intravascular ultrasound energy adds clinical benefit to conventional catheter-directed thrombolysis (CDT) for the treatment of acute PE. A direct comparison between USAT and CDT in this setting is not 


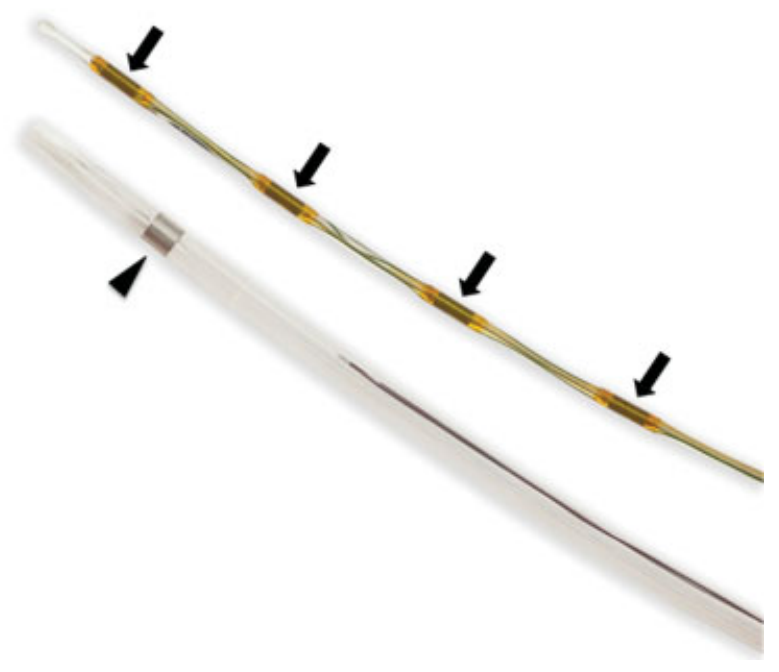

Fig. 2 Tip of the EkoSonic Endovascular System (EKOS Corporation, Bothell, Washington, United States) for ultrasound-assisted catheterdirected thrombolysis (adapted from Engelberger and Kucher ${ }^{34}$ ). The catheter system consists of a 5.2-F multi-side hole drug infusion catheter (treatment zone marker delineated with an arrow head) with two lumens: the first serves for the administration of the thrombolytic drug, and into the second, central lumen, a multi-element ultrasound core wire containing the ultrasound elements (marked with small arrows) is placed. The latter emits low-energy, high-frequency intravascular ultrasound energy along the entire treatment zone.

available, but two studies suggest no major benefit, ${ }^{36,37}$ which would be in line with a recent randomized trial comparing USAT with CDT for the treatment of acute iliofemoral DVT without any difference in acute thrombus load reduction or long-term clinical and ultrasonographic outcomes. ${ }^{38,39}$

Another prospective multi-centre study (PERFECT registry) including a total of 101 acute PE patients treated with different types of catheter-based reperfusion therapies (for intermediate-risk PE mainly CDT and USAT; and for high-risk PE immediate catheter-based (pharmaco-) mechanical clot debulking with or without intra-clot thrombolytic drug injection, followed by CDT or USAT) showed similarly favourable outcomes, with no major bleeding events, despite the fact that an absolute contraindication for systemic thrombolysis was present in $9 \%$ of patients. ${ }^{36}$

In the absence of any direct comparison between catheterbased therapy and systemic thrombolysis, best evidence currently comes from a retrospective analysis of a large national database (National Inpatient Sample). Of the 263,955 subjects identified with acute PE, 4,272 received systemic thrombolysis and 1,455 any kind of catheter-based reperfusion therapy. After propensity matching, in-hospital mortality and overall bleeding risk was similar between both groups, but there was a significant protective effect against intracranial haemorrhage for the catheter therapy (OR, $0.47,95 \% \mathrm{CI}: 0.27-0.82){ }^{40}$

In summary, the main advantage of catheter-based reperfusion therapy over systemic thrombolysis seems to be the favourable safety profile, particularly the very low risk of intracranial haemorrhage even in patients at increased risk for bleeding. The systemic bleeding risk can probably even be improved by using a catheter-based therapy without throm- bolysis ( - Table 2), but only limited data for these techniques are currently available. ${ }^{6}$

\section{Surgical Embolectomy}

Surgical embolectomy was mainly performed as bailout therapy for patients with failed systemic thrombolysis or absolute contraindications of the latter therapy. ${ }^{4}$ Not surprisingly, mortality rates after surgical embolectomy were exceedingly high. However, due to improved surgical techniques and changes in patient selection, the reported pooled mortality rate in a recent meta-analysis of 35\% before 1990 substantially improved to $19 \%$ in the last decade. ${ }^{41}$ In recent years, perioperative mortality rates of $6 \%$ or less have been reported with a rapid multidisciplinary approach even in patients with high-risk PE and significant bleeding risks. ${ }^{4,42}$ Studies directly comparing systemic thrombolysis with surgical embolectomy are lacking, but a randomized controlled non-inferiority trial comparing USAT with surgical embolectomy is currently recruiting patients with intermediate- and high-risk PE in Switzerland (NCT03218410).

\section{Conclusion}

Despite the high incidence of acute PE worldwide, many questions on the optimal management of severe PE remain to be answered. Because of the large spectrum of clinical presentation and outcomes, treatment has to be adapted according to the initial risk stratification. Patients at highrisk for adverse outcomes are likely to benefit from reperfusion therapy, but the optimal way to perform this therapy remains unclear. Systemic thrombolysis is effective, but at the prize of an increased bleeding risk, especially intracranial haemorrhage. Catheter-based reperfusion therapies seem to have a favourable safety profile and are becoming an attractive alternative, but data for patients with high-risk PE are still scarce. The place of catheter-based reperfusion therapy in the treatment of intermediate-risk PE still has to be better defined. Surgical embolectomy remains a valuable treatment option for unstable patients, especially for patients with absolute contraindications for thrombolysis or after failed systemic thrombolysis. With the multitude of treatment options, the recently introduced concept of multidisciplinary Pulmonary Embolism Response Teams (PERT) is gaining widespread acceptance, and will hopefully help in the future to better tailor the different treatments to the individual PE patient. ${ }^{43}$

\section{Conflict of interests}

N. Kucher declares no conflict of interest. R. P. Engelberger is a consultant for EKOS.

\section{References}

1 Heit JA. The epidemiology of venous thromboembolism in the community: implications for prevention and management. J Thromb Thrombolysis 2006;21(01):23-29

2 Goldhaber SZ, Bounameaux H. Pulmonary embolism and deep vein thrombosis. Lancet 2012;379(9828):1835-1846

3 Torbicki A, Perrier A, Konstantinides S, et al; ESC Committee for Practice Guidelines (CPG). Guidelines on the diagnosis and 
management of acute pulmonary embolism: the Task Force for the Diagnosis and Management of Acute Pulmonary Embolism of the European Society of Cardiology (ESC). Eur Heart J 2008;29 (18):2276-2315

4 Konstantinides SV, Torbicki A, Agnelli G, et al. ESC Guidelines on the diagnosis and management of acute pulmonary embolism: the Task Force for the Diagnosis and Management of Acute Pulmonary Embolism of the European Society of Cardiology (ESC) Endorsed by the European Respiratory Society (ERS). Eur Heart J 2014;35(43):3033-3069

5 Kearon C, Akl EA, Ornelas J, et al. Antithrombotic therapy for VTE disease: CHEST guideline and expert panel report. Chest 2016; 149(02):315-352

6 Dudzinski DM, Giri J, Rosenfield K. Interventional treatment of pulmonary embolism. Circ Cardiovasc Interv 2017;10(02): e004345

7 Jiménez D, Aujesky D, Moores L, et al; RIETE Investigators. Simplification of the pulmonary embolism severity index for prognostication in patients with acute symptomatic pulmonary embolism. Arch Intern Med 2010;170(15):1383-1389

8 Kucher N, Rossi E, De Rosa M, Goldhaber SZ. Massive pulmonary embolism. Circulation 2006;113(04):577-582

9 Meyer G, Vicaut E, Danays T, et al; PEITHO Investigators. Fibrinolysis for patients with intermediate-risk pulmonary embolism. $\mathrm{N}$ Engl J Med 2014;370(15):1402-1411

10 Piazza G, Goldhaber SZ. Management of submassive pulmonary embolism. Circulation 2010;122(11):1124-1129

11 Jaff MR, McMurtry MS, Archer SL, et al; American Heart Association Council on Cardiopulmonary, Critical Care, Perioperative and Resuscitation; American Heart Association Council on Peripheral Vascular Disease; American Heart Association Council on Arteriosclerosis, Thrombosis and Vascular Biology. Management of massive and submassive pulmonary embolism, iliofemoral deep vein thrombosis, and chronic thromboembolic pulmonary hypertension: a scientific statement from the American Heart Association. Circulation 2011;123(16):1788-1830

12 Kearon C, Akl EA, Comerota AJ, et al. Antithrombotic Therapy for VTE Disease: Antithrombotic Therapy and Prevention of Thrombosis, 9th ed: American College of Chest Physicians EvidenceBased Clinical Practice Guidelines Chest. 2012;141(2, Suppl): e419S-e94S

13 Engelberger RP, Kucher N. Catheter-based reperfusion treatment of pulmonary embolism. Circulation 2011;124(19):2139-2144

14 Konstantinides SV, Barco S. Prevention of early complications and late consequences after acute pulmonary embolism: focus on reperfusion techniques. Thromb Res 2017:S0049-3848(17) 30352-3

15 Marti C, John G, Konstantinides S, et al. Systemic thrombolytic therapy for acute pulmonary embolism: a systematic review and meta-analysis. Eur Heart J 2015;36(10):605-614

16 Kline JA, Nordenholz KE, Courtney DM, et al. Treatment of submassive pulmonary embolism with tenecteplase or placebo: cardiopulmonary outcomes at 3 months: multicenter doubleblind, placebo-controlled randomized trial. J Thromb Haemost 2014;12(04):459-468

17 Konstantinides SV, Vicaut E, Danays T, et al. Impact of thrombolytic therapy on the long-term outcome of intermediate-risk pulmonary embolism. J Am Coll Cardiol 2017;69(12):1536-1544

18 Klok FA, van der Hulle T, den Exter PL, Lankeit M, Huisman MV, Konstantinides S. The post-PE syndrome: a new concept for chronic complications of pulmonary embolism. Blood Rev 2014;28(06):221-226

19 Kahn SR, Hirsch AM, Akaberi A, et al. Functional and exercise limitations after a first episode of pulmonary embolism: results of the ELOPE Prospective Cohort Study. Chest 2017;151(05):1058-1068

20 Greenfield LJ, Bruce TA, Nichols NB. Transvenous pulmonary embolectomy by catheter device. Ann Surg 1971;174(06): 881-886
21 Schulman S, Kearon C; Subcommittee on Control of Anticoagulation of the Scientific and Standardization Committee of the International Society on Thrombosis and Haemostasis. Definition of major bleeding in clinical investigations of antihemostatic medicinal products in non-surgical patients. J Thromb Haemost 2005;3(04):692-694

22 Spirk D, Husmann M, Hayoz D, et al. Predictors of in-hospital mortality in elderly patients with acute venous thrombo-embolism: the SWIss Venous ThromboEmbolism Registry (SWIVTER). Eur Heart J 2012;33(07):921-926

23 Lin BW, Schreiber DH, Liu G, et al. Therapy and outcomes in massive pulmonary embolism from the Emergency Medicine Pulmonary Embolism in the Real World Registry. Am J Emerg Med 2012;30(09):1774-1781

24 Wang TF, Squizzato A, Dentali F, Ageno W. The role of thrombolytic therapy in pulmonary embolism. Blood 2015;125(14): 2191-2199

25 Chatterjee S, Weinberg I, Yeh RW, et al. Risk factors for intracranial haemorrhage in patients with pulmonary embolism treated with thrombolytic therapy. Development of the PE-CH Score. Thromb Haemost 2017;117(02):246-251

26 Schmitz-Rode T, Kilbinger M, Günther RW. Simulated flow pattern in massive pulmonary embolism: significance for selective intrapulmonary thrombolysis. Cardiovasc Intervent Radiol 1998; 21(03):199-204

27 Kucher N, Boekstegers P, Müller OJ, et al. Randomized, controlled trial of ultrasound-assisted catheter-directed thrombolysis for acute intermediate-risk pulmonary embolism. Circulation 2014; 129(04):479-486

28 Braaten JV, Goss RA, Francis CW. Ultrasound reversibly disaggregates fibrin fibers. Thromb Haemost 1997;78(03):1063-1068

29 Francis CW, Blinc A, Lee S, Cox C. Ultrasound accelerates transport of recombinant tissue plasminogen activator into clots. Ultrasound Med Biol 1995;21(03):419-424

30 GUSTO investigators. An international randomized trial comparing four thrombolytic strategies for acute myocardial infarction. $\mathrm{N}$ Engl J Med 1993;329(10):673-682

31 Piazza G, Hohlfelder B, Jaff MR, et al; SEATTLE II Investigators. A prospective, single-arm, multicenter trial of ultrasound-facilitated, catheter-directed, low-dose fibrinolysis for acute massive and submassive pulmonary embolism: the SEATTLE II Study. JACC Cardiovasc Interv 2015;8(10):1382-1392

32 Kaymaz C, Akbal OY, Tanboga IH, et al. Ultrasound-assisted catheter-directed thrombolysis in high-risk and intermediatehigh-risk pulmonary embolism: a meta-analysis. Curr Vasc Pharmacol 2018;16(02):179-189

33 Lee KA, Cha A, Kumar MH, Rezayat C, Sales CM. Catheter-directed, ultrasound-assisted thrombolysis is a safe and effective treatment for pulmonary embolism, even in high-risk patients. J Vasc Surg Venous Lymphat Disord 2017;5(02):165-170

34 Engelberger RP, Kucher N. Ultrasound-assisted thrombolysis for acute pulmonary embolism: a systematic review. Eur Heart J 2014;35(12):758-764

35 Ganatra S, Majithia A, Yeh YE, Levy MS. Intracranial hemorrhage in a patient with sub-massive pulmonary embolism treated with EkoSonic endovascular system directed thrombolysis. Catheter Cardiovasc Interv 2017;90(03):476-479

36 Kuo WT, Banerjee A, Kim PS, et al. Pulmonary Embolism Response to Fragmentation, Embolectomy, and Catheter Thrombolysis (PERFECT): initial results from a prospective multicenter registry. Chest 2015;148(03):667-673

37 Liang NL, Avgerinos ED, Marone LK, Singh MJ, Makaroun MS, Chaer RA. Comparative outcomes of ultrasound-assisted thrombolysis and standard catheter-directed thrombolysis in the treatment of acute pulmonary embolism. Vasc Endovascular Surg 2016;50(06):405-410

38 Engelberger RP, Stuck A, Spirk D, et al. Ultrasound-assisted versus conventional catheter-directed thrombolysis for acute iliofemoral 
deep vein thrombosis: 1-year follow-up data of a randomizedcontrolled trial. J Thromb Haemost 2017;15(07):1351-1360

39 Engelberger RP, Spirk D, Willenberg T, et al. Ultrasound-assisted versus conventional catheter-directed thrombolysis for acute iliofemoral deep vein thrombosis. Circ Cardiovasc Interv 2015;8 (01):e002027

40 Liang NL, Avgerinos ED, Singh MJ, Makaroun MS, Chaer RA. Systemic thrombolysis increases hemorrhagic stroke risk without survival benefit compared with catheter-directed intervention for the treatment of acute pulmonary embolism. J Vasc Surg Venous Lymphat Disord 2017;5(02):171-176.e1

41 Samoukovic G, Malas T, deVarennes B. The role of pulmonary embolectomy in the treatment of acute pulmonary embolism: a literature review from 1968 to 2008. Interact Cardiovasc Thorac Surg 2010;11(03):265-270

42 Aymard T, Kadner A, Widmer A, et al. Massive pulmonary embolism: surgical embolectomy versus thrombolytic therapyshould surgical indications be revisited? Eur J Cardiothorac Surg 2013;43(01):90-94, discussion 94

43 Dudzinski DM, Piazza G. Multidisciplinary pulmonary embolism response teams. Circulation 2016;133(01):98-103

44 Engelberger RP, Stricker H, Mazzolai L, Kucher N. Schweizer Expertenkommentare zu den 10. ACCP Richtlinien über antithrombotische Therapie: Behandlung der venösen Thromboembolie, Fokus Behandlung der Lungenembolie. Swiss Medical Forum; 2016;16(49-50):1062-1066

Anzeige

NovoEight 250 I.E./500 I.E./1000 I.E./1500 I.E./2000 I.E./3000 I.E. Pulver und Lösungsmittel zur Herstellung einer Injektionslösung, Wirkstoff: Turoctocog alfa. Zusammensetzung: Arzneilich wirksamer Bestandteil: Turoctocog alfa (humaner Blutgerinnungsfaktor VIII (rDNS)). 250/500/1000/1500/2000/3000 I.E. pro Durchstechflasche. Sonstige Bestandteile des Pulvers: Natriumchlorid, L-Histidin, Sucrose, Polysorbat 80, L-Methionin, Calciumchlorid-Dihydrat, Natriumhydroxid, Salzsäure. Sonstige Bestandteile des Lösungsmittels: Natriumchlorid, Wasser für Injektionszwecke. Anwendungsgebiete: Behandlung u. Prophylaxe von Blutungen bei Pat. mit Hämophilie A (angeborener Mangel an Faktor VIII). NovoEight ${ }^{\circledR}$ kann bei allen Altersgruppen angewendet werden. Gegenanzeigen: Überempfindlichkeit gegen den Wirkstoff oder einen der sonstigen Bestandteile. Bekannte allergische Reaktion gegen Hamsterprotein. Nebenwirkungen: Häufig: Reaktionen an Injektionsstelle, erhöhte Leberenzymwerte; gelegentlich: Müdigkeit, Kopfschmerzen, Schwindel, Schlaflosigkeit, Tachykardie, Hypertension, Lymphödem, Ausschlag, Muskelschmerzen oder -steifheit, Hitzegefühl, Fieber; selten: Überempfindlichkeitsreaktionen od. allergische Reaktionen (wie Angioödem, brennendes od. stechendes Gefühl an Injektionsstelle, Schüttelfrost, Hitzegefühl, generalisierte Urtikaria, Kopfschmerzen, Nesselsucht, Hypotonie, Lethargie, Übelkeit, Ruhelosigkeit, Tachykardie, Engegefühl im Brustbereich, Kribbeln, Erbrechen, pfeifendes Atmen), die sich in einigen Fällen zu einer schweren Anaphylaxie (einschließlich Schock) entwickeln können; sehr selten: Entwicklung von Antikörpern chen, pfeifendes Atmen), die sich in einigen Fallen zu einer schweren Anaphylaxie (einschließlich Schock) entwickeln können; sehr selten: Entwicklung von Antikorpern gegen Hamsterproteine mit damit verbundenen Uberempfindlichkeitsreaktionen. Pat. mit Hämophilie A können neutralisierende Antikörper (Hemmkörper) gegen Faktor
VIII entwickeln. Wenn derartige Hemmkörper auftreten, stellt sich dieser Zustand als unzureichendes klinisches Ansprechen dar. In diesen Fällen wird empfohlen ein spezialisiertes Hämophiliezentrum zu kontaktieren. Verschreibungspflichtig. Novo Nordisk A/S, 2880 Bagsvaerd, Dänemark. Stand: November 2017 